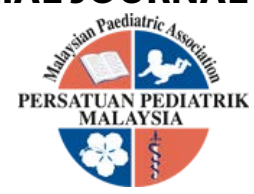

\title{
MANAGEMENT OF PALATAL FRACTURE AND AIRWAY CHALLENGE IN A CHILD - A RED FLAG
}

\author{
Lim Min Jim', Tengku Aszraf Tengku Shaeran', Soon Eu Chong²
}

\begin{abstract}
Airway managements in maxillofacial fracture patients are complex and crucial. Trauma to the maxillofacial region may cause hemorrhage, swelling which may lead to pulmonary aspiration and airway obstruction. Airway managements in maxillofacial fracture patients are complex and crucial. Besides being uncooperative, presence of fractures and soft tissue injuries posed challenges in managing pediatric patient who already have smaller airway opening. This condition is an important red flag which required extra caution from the treating clinicians. A 6-year-old boy was involved in a road traffic accident and presented with profuse bleeding from the oral cavity and nostrils. Physical examination showed oozing of blood with step deformity of the midpalate. Multiple attempts in intubation resulted in failure before succeeding with the aid of suction devices. After intubation was done, intraoral bleeding was successfully managed with transpalatal wiring and nasal packing. The patient was ventilated in the intensive care unit and was extubated two days later. He was discharged well from hospital after one week of admission. Airway management is a rush against time, particularly in a pediatric patient suffering from a palatal fracture. The need for helping hands for suction and child control must be emphasized to ensure the patient's survival.
\end{abstract}

\section{Keywords:}

Palatal Bleeding, Palatal Fracture, Airway Management, Pediatric

\section{Introduction}

Facial fracture rarely occurs in children compared to adults and is often minimally displaced [1]. However, when children suffer from a maxillofacial injury, emergency management may be very challenging. Maxillofacial trauma involving a fracture of the facial bone can be dangerous due to the location of the injury, which is near to the brain and airway [2] and other concomitant traumatic injury [3]. Intubation can be a major challenge as the fracture of the midface complicates the route for intubation. Airway obstruction can be due to fractured teeth, bone fragments, foreign bodies, soft-tissue oedema, tissue prolapse, or bony interference [4].

Nevertheless, vomitus and uncontrolled haemorrhage pose a high risk of pulmonary aspiration. With the addition of anatomical challenges in children (3) and being
Received: 1 July 2019; Accepted revised manuscript: 1 October 2019

Published online: 24 November 2019 uncooperative, intubation in maxillofacial trauma in children may be a big challenge. However, it is rarely reported. We report a case of a paediatric patient sustaining a palatal fracture, which had led to the crisis of difficult intubation.

\section{Case report}

A 6-year-old boy was involved in a road traffic accident when he was hit by a truck while cycling.

\footnotetext{
'Oral \& Maxillofacial Surgery Unit, Hospital Tanah Merah, Kementerian Kesihatan Malaysia, Kelantan, Malaysia.

${ }^{2}$ Regenerative Medicine Cluster, Advanced Medical and Dental Institute, Universiti Sains Malaysia Malaysia

Corresponding author: Dr. Lim Min Jim, Oral \& Maxillofacial Surgery Unit, Hospital Tanah Merah, Kementerian Kesihatan Malaysia, Kelantan, Malaysia

Tel: 609-9557684; Email: minjimlim@hotmail.com
} 
He presented to the hospital with Glasgow Coma Scale (GCS) score of 14 (E3 V5 M6) without any extra-oral injury. However, there was profuse bleeding from the oral cavity and nostril. He had a few episodes of vomiting of blood and was restless due to pain. Detailed physical examination revealed a split in palatal mucosa with step deformity at the midline of the hard palate. Blood can constantly be seen oozing from the palate (Fig. 1).

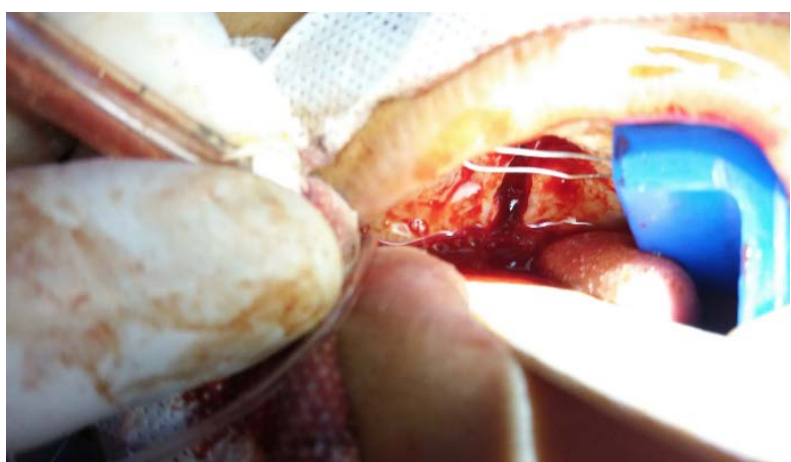

Figure 1. Blood oozing from the palatal fracture site. Photo taken after the child was successfully intubated

Packing with adrenaline-soaked gauze was attempted to stop the bleeding but to no avail. Transpalatal wiring for stabilization of the palatal fracture could not be done as the patient was too restless and uncooperative. In fear of pulmonary aspiration, intubation was decided for airway protection by the emergency physician. The patient was given intravenous (IV) morphine 2.5 $\mathrm{mg}$, IV midazolam 5mg, followed by cricoid pressure and IV suxamethonium 15mg. However, the emergency physicians were unable to visualize the vocal cord due to bleeding and obstructed view by the soft tissue trauma. Blind intubation was attempted but had failed. The child was able to be ventilated using jaw trust, and frequent suction was required. A total of five attempts of tracheal intubation before the child was successfully intubated with a size $5.0 \mathrm{~mm}$ internal diameter endotracheal tube (Murphy, Unomedical, Malaysia) aided with a stylet and an extra suction device to help the intubation procedure. Fortunately, there was no significant desaturation in oxygen saturation throughout the procedure.

After the intubation, intraoral bleeding was successfully ceased via transpalatal wiring and nasal packing. Arterial blood gas showed $\mathrm{pH}$ 7.301, PCO2 47.5 mm Hg, PaO2 171 mmHg, HCO3 $23.4 \mathrm{mmol} / \mathrm{L}$ and $\mathrm{BE}-3.0$. Blood pressure was $98 / 52 \mathrm{mmHg}$ with pulse of 112 beats per minute. CT scan of the head confirmed the diagnosis of Le
Fort 1 maxillary fracture with incomplete palatal fracture involving posterior part of the palate (Fig. 2). The patient was ventilated in the intensive care unit and was extubated two days later. He was discharged well from hospital after one week of admission.

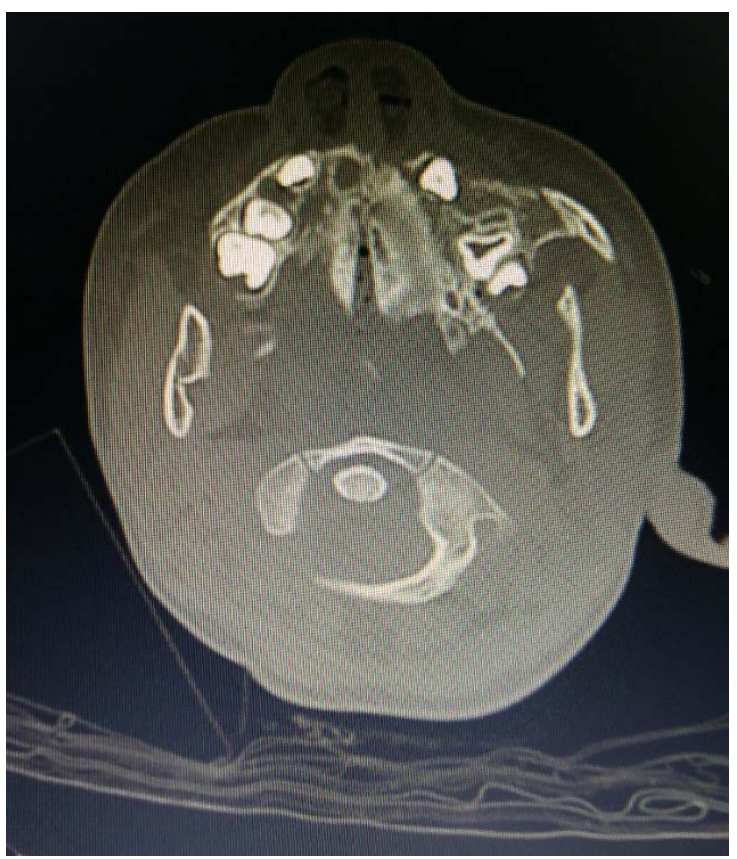

Figure 2. Axial view showing fracture at the posterior palatal region, ending at nasopalatine foramen

\section{Discussion}

Children's airway has unique anatomical variation from adult. They have a large head and prominent occiput, therefore a higher tendency of the neck to be in flexion position causing airway obstruction. They have a relatively larger tongue which may obstruct the airway and therefore a difficult laryngoscopy. The epiglottis of a child is funnel shape and floppy, the larynx is more "anteriorly placed" and with a smaller glottis opening. All these factors contribute to the suboptimal view of the vocal cord during laryngoscopy [5].

Le Fort maxillary fractures are uncommon in patients below six years old. Children who sustained maxillary fractures are risky in having compromised airway from swelling and mechanical obstruction due to the relatively small diameter of the airway. Hence the need for airway maintenance, control of haemorrhage and early resuscitation are critical and time-dependent in children than adults [1].

Airway management can also be very challenging in maxillofacial trauma patient due to its unique 
presentation. Airway obstruction in maxillofacial trauma can be caused by prolapse, soft-tissue oedema or hematoma, and severe haemorrhage [4]. Maxillofacial trauma is prone to massive haemorrhage as many blood vessels are present in facial region, and severe epistaxis can arise from the maxillary artery [6].

In this case, communication between the oral cavity and the nasal cavity was established due to the break-in palatal mucosa and palatal bone fracture. Bleeding from the nasal and maxillary sinus region flowed into the oral cavity leading to the increase intraoral blood pooling. Therefore, intraoral injury, palatal fracture, and bleeding in this child had caused a combination of difficult situations. The soft tissue injury and swelling further obscure the glottis view.

Video laryngoscope, fiber optic intubation which is recommended in difficult airway [7-8] is of no use because bleeding can hinder glottic visualization, especially in a video-assisted device. Laryngeal mask airway, which is also recommended in fail intubation algorithm [7] is also contraindicated because of the risk of aspiration in this patient. In this case, an effective suction is absolute importance. Extra help to control the child and situation, external laryngeal manipulation may help to aid in intubation.

Midfacial fractures are broadly categorized into Le fort I, Le fort II and Le fort III. Le Fort I fracture is horizontal fractures involving all walls of bilateral maxillary sinuses and the pterygoid plates. Le fort I fracture results in detachment of hard palate and maxillary alveolar bone form the midface. Le fort II is a pyramidal fracture involving zygomaticomaxillary suture, nasofrontal suture and pterygoid process of the sphenoid which results in injuries to the eye, base of skull, lacrimal system and sinus obstruction. Le fort III fracture is the separation of midface from the cranium due to involvement of nasal bone, all orbital walls, pterygoid process and zygomatic arch [9]. $\mathrm{Ng}$ et al. noted that airway obstruction in patients' with Le fort injuries were often due to bleeding into upper airway from multiple source [10]. Bagheri et al. found that Le fort III injuries requires tracheostomy for airway management more than Le fort I injuries, followed by Le fort II which has the least probability of requiring tracheostomy. However, it is noted that Le fort II and III had higher probability of requiring ICU admission or immediate operative intervention compared to Le fort I [11].

\section{Conclusion}

Airway management is a rush against time, which is crucial in dictating patient survival. The notion of having a maxillofacial fracture in paediatric patient, especially a palatal fracture, should raise a warning in physician for difficult intubation. The need of helping hands for suction and child control must be emphasized to ensure the patient's survival.

\section{Acknowledgement}

We would like to thank the Director General of Health Malaysia for his permission to publish this article. We would also extend our appreciation for the Emergency Department of Hospital Tanah Merah. We also thank Madam Lee Jong Koh for critical reading and useful comments on this manuscript.

\section{Funding}

None declared

\section{Competing interests}

The authors declared no competing interests.

\section{Ethical approval}

Institutional Review Board approval is not required at the authors' institutions for the presentation of a single case report because written consent has been obtained.

\section{Patient consent}

Written consent was obtained from patient's father.

\section{References}

[1] Zimmermann CE, Troulis MJ, Kaban LB. Pediatric facial fractures: recent advances in prevention, diagnosis and management. Int J Oral Maxillofac Surg. 2006;35(1):2-13.

[2] Krausz AA, El-Naaj IA, Barak M. Maxillofacial trauma patient: coping with the difficult airway. World J Emerg Surg. 2009;4:21.

[3] Haug $\mathrm{RH}$, Foss J. Maxillofacial injuries in the pediatric patient. Oral Surgery, Oral Medicine, Oral Pathology, Oral Radiology, and Endodontology. 2000;90(2):126-134.

[4] Kellman RM, Losquadro WD. Comprehensive airway management of patients with maxillofacial trauma. Craniomaxillofac Trauma Reconstr. 2008;1(1):39-47.

[5] Tripathi DSS, Pal DJK, Singh DRR, Awasthi DS, Mishra DSP. Airway management of trauma 
patient of paediatric age group. International Journal of Life-Sciences Scientific Research. 2016;2(6).

[6] Jose A, Nagori SA, Agarwal B, Bhutia O, Roychoudhury A. Management of maxillofacial trauma in emergency: An update of challenges and controversies. J Emerg Trauma Shock. 2016;9(2):73-80.

[7] Frerk C, Mitchell VS, McNarry AF, et al. Difficult airway society 2015 guidelines for management of unanticipated difficult intubation in adults. British Journal of Anaesthesia. 2015;115(6):827-848.

[8] Salama A, Hemy A, Raouf A, Saleh N, Rady S. C-MAC Video laryngoscopy versus flexible fiberoptic laryngoscopy in patients with anticipated difficult airway: A Randomized Controlled Trial. J Anesth Pati Care. 2015;1(1):101.

[9] Phillips, Bradley J, and Lauren M Turco. "Le Fort fractures: A collective review." Bulletin of emergency and trauma vol. 5,4 (2017): 221230.

[10] Ng M, Saadat D, Sinha UK: Managing the emergency airway in Le Fort fractures. J Craniomaxillofac Trauma 4:38, 1998.

[11] Bagheri SC, Holmgren E, Kademani D, Hommer L, Bell RB, Potter BE, Dierks EJ. Comparison of the severity of bilateral Le Fort injuries in isolated midface trauma. J Oral Maxillofac Surg. 2005; 63: 1123-1129. 